\title{
MOTIVOS DE FLORES EN KEROS COLONIALES: IMAGEN Y SIGNIFICADO
}

\author{
THE FLORAL MOTIF IN COLONIAL KEROS: \\ IMAGES AND MEANING
}

Eleonora Mulvany*

\begin{abstract}
Presentamos los resultados de un estudio de los motivos de flores en los keros coloniales. En nuestro estudio proponemos una similitud semántica entre los motivos de keros y unkus de este período. Basándonos en estudios etnobotánicos y etnohistóricos encontramos que las flores fueron incorporadas en diferentes actos rituales vinculados a la organización social. En nuestro análisis postulamos vinculaciones entre el calendario ritual y el calendario floral. Proponemos que las flores en los keros coloniales son metáforas polisémicas, relacionadas con conceptos significativos de mediación y orden.
\end{abstract}

Palabras claves: keros, período Colonial, flores, calendario floral, calendario ritual, metáforas, mediación.

This study presents the results of an analysis of the floral motif found on colonial keros. In the paper, I note a semantic similarity between the motifs observed on keros and unkus (male tunics) of this period. Ethnobotanical and ethnohistorical data indicate that the same flowers represented on these objects were utilized in various ritual acts linked to social organization. A possible relationship between the ritual calendar and the growing cycle of these plants is also suggested. I conclude that the flowers depicted on the colonial keros were polisemic metaphors associated with concepts of order and mediation.

Key words: keros, Colonial period, flowers, flower calendar, ritual calendar, metaphors.

En este trabajo estudiamos un aspecto de la cultura material, la decoración de la superficie externa de los keros hispano indígenas o coloniales. El estudio se centra en el motivo de flores con la finalidad de comprender la relación entre cultura material e ideología. Consideramos un marco en el que la producción material es simultánea con la producción de significado, que la tecnología es un acto significativo en el que la secuencia de actividades interrelaciona lo material y lo ideológico (Dobres 2000:7). Anteriormente hemos analizado el tema del contexto ritual en el empleo de flores durante los Horizontes temprano y medio y su vinculación con diseños en diferentes artefactos y soportes materiales (Mulvany 1984, 1995). Las investigaciones realizadas por Letchman sobre metalurgia Moche analizan la relación entre los sistemas cognitivos, como expresión de la ideología, y la tecnología como medio para la obtención de resultados acordes con los sistemas de creencias y valores. Los trabajos de Cereceda sobre tecnología textil exploran el tema de la belleza como elemento mediador y la construcción de identidad en relación con la organización social (Cereceda 1988, 1990; Letchman 1984, 1997). Dobres señala que las investigaciones sobre este tema proponen una elección de las técnicas más relacionadas con preferencias culturales, "saberes", que con las mismas propiedades físicas o químicas de los materiales (Dobres 2000:7).

\section{Los Keros Coloniales}

El vocablo kero o qero era utilizado para denominar vasijas para beber y brindar en diferentes celebraciones rituales. Los vocabularios de comienzos del siglo XVII sugieren que inicialmente los vocablos qero (o kero) designaban únicamente los vasos de madera; los elaborados con plata eran conocidos como aquilla y los de oro como ccori aquilla (González Holguín 1989 [1608], Parte II: 689). Soldi señaló que su producción posiblemente estuvo a cargo de especialistas, como ocurría entre los Quero (León de Huánuco) quienes entregaban bebedores de palo al estado Inka, ya sea en calidad de camayoc o a través del sistema de mit'a (1997:8).

Morfológicamente son vasijas restringidas independientes, de contorno simple hiperboloide o vasijas no restringidas de contorno simple, sección

* Facultad de Humanidades - CEPIHA - CIUNSa - Universidad Nacional de Salta, Argentina. pluma@uolsinectis.com.ar 
de cono, elaboradas en metal, cerámica y madera. Su superficie externa puede presentar o carecer de decoración. Su elaboracion perduró a través del tiempo, desde el Horizonte medio hasta comienzos del período de Independencia (Rowe 1961). Incluso durante el siglo XX algunas comunidades de pastores dedicados a la cría de llamas y alpaca, como Chillwa y Urayuma, ubicadas en la cordillera de la provincia de Apurímac (Perú), poseían antiguos keros de madera, especialmente usados en las celebraciones rituales de señalamiento, en los momentos de apareamiento y trasquila de llamas. Los integrantes de estas comunidades los relacionaban con poderes mágicos y por ello tenían un carácter sagrado. Los ejemplares, transmitidos de una generación a la siguiente, habían sido cuidadosamente conservados, adoptando medidas de preservación en aquellos vasos que tenían fisuras, fortaleciéndolos con tendones de alpaca, brea y grasa de llama (Soldi 1997).

Posiblemente desde el Horizonte medio, los keros fueron usados para consumir chicha, denominación introducida por los españoles para designar la bebida sagrada elaborada con maíz. A mediados del siglo XVI Betanzos relató que

cuando un señor/a visitaba otro/a señor/a el tanto el visitante hacia servir dos vasos de "chicha" y ..." el uno da a beber al tal señor que visita y el otro se bebe el tal señor o señora que la chicha da...es la mayor honra que entre ellos se usa"... (Betanzos 1987 [1551]:72-73).

En los asentamientos arqueológicos incaicos estos vasos generalmente son hallados constituyendo conjuntos de pares idénticos (Rowe 1961). Los keros junto a los unkus constituían un único presente otorgado por el Inka en situaciones de alianza con diferentes etnias, y... "en un nivel de comprensión andina, eran considerados como un conjunto de objetos simbólicos que se referían uno al otro y que juntos expresaban el significado del presente inka"...que durante las celebraciones rituales eran usados simultáneamente para.... "recordar, a través de la relación simbólica entre ellos...hechos históricos" (Cummins 1993:122).

Los keros han sido estudiados y clasificados por diferentes investigadores. Rowe es uno de los primeros que señaló que la tradición artística incaica no finalizó al momento de la conquista española, sino que continuó en el período Colonial a través de los tejidos y keros (1961:317). Propuso una clasificación basada en atributos relacionados con técnicas y motivos usados sobre la superficie externa de los ejemplares. Teniendo en cuenta información arqueológica e histórica planteó cuatro estilos con valor temporal: Inka, Transición, Colonial Estilo Formal, Colonial Estilo Libre, señalando que fueron elaborados al menos hasta 1821, fecha de inicio de la República del Perú (Rowe 1961). Posteriormente Gisbert propuso cinco estilos basados en las técnicas de decoración: incisa, incisa y pintada, pintada, con incrustación de estaño y/o plata y escultórica (Gisbert 1999a:88), integrados en una secuencia temporal en fases, modificando la de Rowe: Geométrico-Inciso, Virreinal arcaico (Formal según Rowe), Virreinal tardío (Libre según Rowe) y Republicano (Gisbert 1999a: 87). Citando a Rowe, señala que durante el Horizonte tardío los keros eran básicamente decorados por medio de incisiones, mientras que en los momentos coloniales se caracterizan por su policromía (Gisbert 1999a; Rowe 1961).

En el marco de los estudios etnobotánicos las contribuciones incluyen la identificación de las especies usadas como materia prima para la elaboración de estos vasos y de aquellas representadas en los motivos fitomorfos (Soldi 1997; Vargas 1981). Las maderas usadas para su elaboración son de grano fino y fibras compactas, posiblemente elegidas porque facilitan el trabajo de taraceo y la aplicación de los barnices, a la vez que son más resistentes a la acción de insectos como polilla (Soldi 1997:85). Las especies incluyen Escallonia resinosa (Chachacoma), cuya madera actualmente es utilizada en ebanistería; de peso y dureza mediana; su duramen es rojizo pardo y la albura rosa pálida. Otros ejemplares están elaborados con $\mathrm{Al}$ nus jorullensis (Lambrán) y Cedrela odorata (Cedro), cuya madera es más liviana y blanda; se incluyen palmas, principalmente especies de Bactris (Soldi 1997:85; Vargas 1981).

Los keros coloniales se caracterizan por un conjunto de motivos ejecutados mediante técnica de rebaje suave e incrustación de pintura. Las áreas de diseño fueron delineadas y rebajadas, rellenándolas con un barniz brillante y liso parecido a la laca. Los colores posiblemente se obtuvieron de pigmentos que parecen ser sustancias minerales, tales como ocres, mezclados con materiales de origen vegetal, posiblemente raíces, tallos, hojas y frutos, finamente pulverizados y mezclados con alguna resina ob- 
tenida a partir de la exudación de árboles de los bosques húmedos y secos, ubicados al este y oeste de los Andes, en los valles interandinos y la costa desértica. La mezcla mineral y vegetal posiblemente se calentó para obtener la fluidez necesaria para aplicarlo, desecando rápidamente (Soldi 1997:85; Vargas 1981:314). El fondo puede tener el color natural de la madera, o puede ser aclarado u oscurecido mediante tintes, o pigmentado en color verde, negro y blanco (Vargas 1981:314).

La estructura decorativa de los keros hispano indígenas o coloniales fue resuelta de tres formas: a) motivos dispuestos en paneles horizontales, b) diseños en paneles verticales, c) diseños que ocupan toda la superficie como si constituyeran un solo panel vertical (Cummins 1993; Gisbert 1999a; Soldi 1997; Vargas 1981). La decoración más frecuente se dispone en dos a cinco paneles horizontales, de los cuales el central generalmente está formado por una serie de pequeños motivos geométricos encerrados en campos cuadrangulares, romboidales o triangulares identificados como tocapus (Gisbert 1999a; Rowe 1961; Soldi 1997).

Se han diferenciado los estilos coloniales Formal y Libre básicamente por la configuración del panel superior. En el Estilo Formal (Rowe) o Virreinal arcaico (Gisbert) la presencia de dos arco iris, originados en la fauces de dos pumas, generan cuatro campos, dentro de los cuales se observan dos motivos antropomorfos, que diferentes autores consideran representan al Inka y la Coya; en el punto de unión de los arcos puede existir un motivo fitomorfo o una tercera representación femenina. En el estilo Virreinal tardío o Libre aumenta el número de motivos antropomorfos cuya configuración es más curvilínea y suave. Generalmente los motivos están pintados en negro, blanco, marrón y rojo (Gisbert 1999a; Gisbert et al. 1992; Rowe 1961).

Un elemento presente en los diferentes estilos de keros coloniales está integrado por motivos de plantas, particularmente hojas y flores. Generalmente se disponen en la base o en el borde, y excepcionalmente en la parte media, como Vargas señala, aunque él desconoce la causa (Vargas 1981:314). Algunos ejemplares presentan dos o más elementos fitomorfos, otros ofrecen la repetición de un solo motivo floral distribuido sobre toda la superficie del recipiente, pero la presentación más frecuente es aquella en la que las flores se relacionan con el panel basal o inferior (Gisbert 1999a; Rowe 1961; Soldi 1997; Vargas 1981).

\section{Los Keros en una Sociedad en Transformación}

Básicamente la investigación sobre los keros coloniales se ha centrado en el panel superior. Estos estudios, abordados por diferentes investigadores, consideran que los motivos han sido configurados siguiendo pautas europeas. En este marco los conjuntos de imágenes han sido interpretados como integrando una secuencia de escenas descriptivas, que es factible "leer" como si constituyeran representaciones de acciones que "narran", entre otros, mitos, relatos histórico-míticos, celebraciones rituales o batallas combinando elementos nativos y europeos (Cummins 1993; Estenssoro 1993; Gisbert 1999a y b; Stastny 1993).

Las investigaciones sobre el período Hispano Indígena analizan los cambios económicos, demográficos, sociales, políticos y religiosos, destacando que estuvieron acompañados por una política oficial que hizo uso intensivo y extensivo de las imágenes. El discurso político y religioso, conjuntamente con la extirpación de idolatrías, produjo nuevas fronteras sociales y simbólicas (Cummins 1993; Estenssoro 1993; Gisbert 1999a y b; Gisbert et al. 1992; Rowe 1961). Nuevas formas sociales se vincularon con otros modos de transmitir información, y en el seno de una sociedad colonial en formación, en la que la mayor parte de la población era iletrada, la transferencia de información se hizo principalmente a través de la imagen.

Siguiendo las recomendaciones del Concilio de Trento, la Iglesia Católica enseñó dogmas y principios del cristianismo a través de autos sacramentales y artes plásticas usando metáforas y analogías (Gisbert 1999b). La pintura apoyó la prédica (..."enseñen diligentemente los obispos... por medio de la historia de los misterios... expresadas en pinturas y en otras imágenes..." en Estenssoro 1997:158). El poder político utilizó las imágenes para justificar la conquista con ayuda divina, o para representar la política de continuidad de la corona española con el estado Inka (Estenssoro 1993:160). En este contexto, la plástica fue usada como testimonio de la realidad y la imagen fue considerada como sinónimo de verdad (Estenssoro 1993:158). El arte oficial se impuso sobre las manifestaciones nativas, paulatina o violentamente anuladas. En 1574 Toledo dictó una serie de ordenanzas, una de las cuales relacionaba la dificultad en la conversión de los nativos con el uso de motivos de aves y 
animales pintados o incididos en los keros, por lo que expresamente impuso la prohibición de usar estas "figuras" obligando a que fueran eliminados; la misma ordenanza imponía que los indios plateros fueran concentrados en un lugar de Cuzco con la finalidad de impedir que al elaborar los keros de plata los decoraran con "figuras e ídolos" (Gisbert 1999a:86). Para este objetivo Toledo habría mandado edificar un gran galpón en la Plaza del Hospital de Cuzco, donde se concentraron los plateros bajo la supervisión de un español (Gisbert 1999a:86).

Estos procesos durante los siglos XVI y XVII estuvieron acompañados por modificaciones en las celebraciones rituales de las etnias, como su "enmascaramiento" al realizarlas en forma coincidente con celebraciones cristianas; ceremonias como el Intip Raymi se hicieron coincidir durante el Corpus Christi (Polo de Ondegardo en Arriaga 1999 [1621]). Otra modificación fue realizar estas celebraciones en lugares apartados, o ejecutarlas totalmente en secreto, con la finalidad de mantenerlas ocultas a los españoles (Betanzos 1987 [1551]:70; Molina "El Cuzqueño" 1959 [1575]; Murúa 1946 [1590]). Este ocultamiento fue relativamente exitoso en la costa posiblemente hasta mediados del siglo XVII. Arriaga relataba que los pueblos y ayllus conservaban sus wakas, para las cuales almacenaban ofrendas y realizaban celebraciones rituales periódicas, reunidos por "ayllos y parcialidades" (Arriaga 1999 [1621]:20-21).

En este contexto, la bebida ceremonial continuó constituyendo una parte importante de las celebraciones en las comunidades. De acuerdo a Arriaga ..."la principal ofrenda y la mejor y la mayor parte de sus sacrificios es la chicha... con ella comienzan todas las fiestas de las huacas... dan de beber a las huacas ... para esta chicha hay los particulares ministros"... (Arriaga 1999 [1621]:50) (Subrayado nuestro).

Se ha señalado que las modificaciones en los keros de este período se relacionan fundamentalmente con los motivos del panel superior, en los que los personajes antropomorfos integraron vestimenta a la usanza española, pintados según convenciones europeas e incorporando elementos de los mitos europeos (Cummins 1993; Estenssoro 1993; Gisbert 1999a y b; Gisbert et al. 1992; Rowe 1961). Unas décadas después de la conquista española los keros ya no eran de uso exclusivo por parte de la elite, y su producción se vinculaba a circuitos de venta o intercambio (Soldi 1997:85).

En este contexto, los tejidos también experimentaron variaciones incluyendo la técnica de tapiz. Ésta había sido usada para la elaboración de los unkus durante el Horizonte tardío y constituía una producción prestigiosa, cuya estandarización en diseños, técnica, medidas sugiere una producción especializada a cargo de cumbicamayos reunidos en talleres, destinada a la redistribución (Iriarte 1993:53 citando a Rowe). Durante el período Colonial perduró la tradición de tapiz con la introducción de modificaciones, cubriendo la demanda de tapices por parte de los españoles (Gisbert et al. 1992; Iriarte 1993). Iriarte ha vinculado las modificaciones en los unkus con cambios en el contexto social; los usuarios ya no recibían tejidos en un marco de reciprocidad sino que los encargaban directamente al tejedor (Iriarte 1993:54).

En los unkus coloniales perduró la distribución de los tocapus en el canesú, bandas de la cintura, bandas verticales centrales, ruedo, costuras laterales y/o aislados en el cuerpo de la túnica (Iriarte 1993:61), pero la introducción de estos motivos en tocados o aislados en el cuerpo del unku de las imágenes masculinas constituyó una innovación colonial (Iriarte 1993).

Otra innovación colonial en los textiles es la incorporación de las flores que decoran unkus, llikllas y acsus, pertenecientes a personas de linaje elevado (Iriarte 1993:68). Los elementos florales, tejidos o bordados, se disponían en posición verti$\mathrm{cal}$, en una secuencia en la zona del ruedo o como motivos dispersos en el cuerpo de la vestimenta masculina y femenina (Iriarte 1993:58, 65, 67).

\section{Keros y Unkus, ¿Un Mismo Significado?}

Estas modificaciones en tejidos y keros parecen haber estado asociadas a la introducción de motivos fitomorfos. Encontramos varios elementos comunes en el uso de flores en vasos y tejidos.

Uno de ellos es que las flores se disponen en la banda inferior de keros y en el ruedo de unkus coloniales. Un segundo atributo se relaciona con el hecho que generalmente se representa una sola clase de flor (especie), en una secuencia repetitiva que sugiere una sintaxis similar a la que podemos observar en el ordenamiento de los tocapus en la banda central. Cummins señaló que la banda central con tocapus en los recipientes ocupa 
una posición equivalente en los unkus (1993:128). Hemos mencionado que Vargas describe algunos ejemplares donde los motivos fitomorfos se distribuyen en una banda central. Postulamos que la secuencia repetitiva de flores en la banda central de los vasos es semánticamente equivalente a la banda central de tocapus, en los tejidos, sugiriendo una posible paridad de flores y tocapus. Esta disposición continuada de un mismo elemento contrasta con la configuración bilateral o asimétrica de la banda superior, particularmente en los vasos de Estilo Formal.

Un tercer rasgo se relaciona con la posición de las flores en los vasos. Están representadas en posición vertical, como si estuvieran erguidas, su cáliz y corola en el extremo superior del diseño y el tallo en el inferior; la base de este último se apoya sobre la línea inferior que delimita la misma banda. Esta posición y la secuencia repetitiva son equivalentes a las que Iriarte describe e ilustra para los motivos fitomorfos en el ruedo de los textiles (Iriarte 1993:67).

Otro elemento compartido por tejidos y vasos coloniales se relaciona con las especies de las flores representadas. Los nombres vulgares de las flores identificadas etnobotánicamente en los keros son kantuta, chinchircuma, ñucchu, amancay, chiwanway, maywa y fucsia (Infante Vera 1962; Towle 1961; Vargas 1981). En los textiles se mencionan entre otras ñucchus, trifolias y cuadrifolias (Iriarte 1993:58). Las flores en las vasijas generalmente están representadas de perfil y pueden ser descritas como trifolias o cuadrifolias, por lo que las referencias de Iriarte en los textiles coloniales posiblemente representen las mismas especies que decoran los keros del mismo período.

Otro elemento en común es que las representaciones antropomorfas y zoomorfas en los textiles ocupan el campo del canesú de los unkus (Iriarte 1993:73), una posición llamativamente similar a la que ocupan los motivos zoomorfos y antropomorfos en la banda superior de los keros.

Este conjunto de elementos expresados en dos tipos de soportes diferentes, pero con equivalencias en contenidos temáticos y disposición en la estructura general, sugieren una continuidad, posiblemente relacionada con procesos cognitivos, vinculando distintos artefactos sobre diferentes soportes, que posiblemente no sea casual (Figura 1). Lo anterior nos lleva a proponer que la decoración de los keros no sólo es similar a los unkus, sino que interpretamos que los keros representen unkus o viceversa.

\section{Las Flores como Metáforas}

Si bien en los keros el tamaño relativo de la banda superior sugiere que las escenas representadas parecen llevar el peso de la decoración, consideramos que la posición y tamaño de las flores en la parte inferior, su coloración brillante, su reiteración a la manera de un tocapu pueden ser significativas, captando una mirada diferente y dirigiendo la atención hacia otra "lectura".

Las características formales de las flores en posición vertical sobre una línea de la banda inferior, su secuencia repetitiva, refieren a un ordenamiento de elementos como en una guirnalda. El "llauto" de los Inkas también era denominado $P i$ llu, y Chhantascca Pillu era una "corona de flores". Por su parte, Chhantani significaba "Hazer ramilletes", o "Componer por orden cosas varias en una", como "Componer vn altar con joyas, ramilletes o un santo o vnas andas" y componer "toda cosa galana” (González Holguín 1989 [1608]; Parte I: 95, 96).

Las "coronas" o tocados con flores eran usados por varones adultos, integrantes de los grupos de linajes elevados, y que realizaban tareas administrativas en el estado Inka. Una semejanza que se ve reforzada porque en keros y tocados se utilizan las mismas clases de flores (Mulvany 2000-2002).

Estamos ante una imagen en la que el artesano que taraceaba y pintaba las flores en la base del kero elaboraba simultáneamente una guirnalda (Componer por orden cosas varias en una). Esta imagen remitía a otra porque chantani también era "Criar de nada y dar forma de nada y de cosa sin ser" (González Holguín 1989 [1608], Primera parte: 95). Un conjunto de gestos relacionados con actos de creación.

Chantani también se relaciona con otras cualidades, que definían características personales, particularmente las que definían una persona como "acertada, compuesta, concertada", es decir, alguien cuyas cualidades personales son cordura, tino, destreza, mesura, circunspección, moderación y capacidad para componer y acordar diferentes partes. Los varones adultos usaban estos tocados con flores durante las celebraciones rituales, y se esperaba que entre sus cualidades personales tuvieran 


\begin{tabular}{|c|}
\hline CANESÚ \\
REPRESENTACIONES \\
ZOOMORFAS Y \\
ANTROPOMORFAS \\
\hline PAMPA \\
\hline BANDA CENTRAL \\
TOCAPUS \\
\hline PAMPA \\
\hline RUEDO CON FLORES \\
\hline
\end{tabular}

\begin{tabular}{|c|}
\hline BANDA SUPERIOR \\
REPRESENTACIONES \\
ZOOMORFAS Y \\
ANTROPOMORFAS \\
¿PAMPA? \\
BANDA CENTRAL \\
TOCAPUS \\
¿PAMPA? \\
BANDA INFERIOR CON \\
FLORES
\end{tabular}

Figura 1. Distribución espacial de motivos en unkus y keros (Fuentes: Cummins 1993; Gisbert et al. 1992; Iriarte 1993; Rowe 1961; Soldi 1997; Vargas 1981).

Spatial distribution of motifs associated with unkus and keros (after Cummins 1993; Gisbert et al. 1992; Iriarte 1993; Rowe 1961; Soldi 1997; Vargas 1981).

cordura, tino, destreza, mesura, circunspección, moderación y capacidad para componer y acordar entre diferentes partes (Mulvany 2000-2002). Los keros eran recipientes usados por varones. Una posible interpretación sobre el uso de flores en los keros es que permitirían establecer una vinculación con estas imágenes de hombres mesurados y mediadores.

Sólo algunas flores, referidas por los cronistas, eran consideradas "plumajes" (Mulvany 20002002). Varios autores han propuesto identificaciones de las especies de flores usadas en keros (Infante Vera 1962; Towle 1961; Vargas 1981). Confrontando nombres vulgares, específicos y coloración, observamos que los colores predominantes abarcan una gama de fucsias, rojos, naranjas, amarillos y cremas y blancos. Algunas especies son simultáneamente rojas y amarillas como Kantuta y Chiwanway (Tabla 1).

Varias fuentes sugieren que estos tonos estaban asociados con la persona del Inka. Eran los colores de las borlas que colgaban de la mascapaicha real, rojo para el Zapa Inka y amarillo para su heredero (Garcilaso de la Vega 1976, Tomo II, Libro Sexto, Capítulo XXVII: 60). Una característica de éstos es que nos ofrecen un fuerte contraste óptico entre el rojo y el amarillo. Algunos estudios relacionan el contraste de colores oscuros y claros con el concepto de missa (Flores Ochoa 1997:720721). Otro significado de missa es "venturoso en el juego" (Flores Ochoa 1997). Missa se relaciona con sami, que designa aquellas personas que poseen protección sobrenatural y por ello pueden invocar a las divinidades (Flores Ochoa 1997:723). A través de este contraste del color de las flores nos encontramos con una imagen que encierra dos significados: atraer ventura, protección sobrenatural, para otorgar virtudes excepcionales a quienes los usan, y atraer la suerte, la posibilidad de ser venturosos en el juego y en la guerra.

Anteriormente hemos analizado otro de los posibles significados de las flores como metáfora de 
Tabla 1. Flores, coloración y designación vulgar y científica.

Scientific and common names of the flowers discussed.

\begin{tabular}{|c|c|c|}
\hline Nombre vulgar & Nombre científico & Color de la flor \\
\hline$K^{\prime} a n t u$, kantuta & Cantua buxifolia Juss. ex. Lam. & $\begin{array}{l}\text { Flores tubulares rojas y } \\
\text { amarillas }\end{array}$ \\
\hline $\begin{array}{c}\text { ccantu, decanto, ccellmo, flor del } \\
\text { inka }\end{array}$ & $\begin{array}{c}\text { C. tomentosa Cav., Perighragmos } \\
\text { C. dependens }\end{array}$ & $\begin{array}{l}\text { Cáliz verde o purpúreo. } \\
\text { Corola rojo-purpúreo }\end{array}$ \\
\hline K'antu, kantuta & C. buxifolia Juss. ex Lam. & Rosa ciclamen \\
\hline Chinchircuma & $\begin{array}{l}\text { Mutisia viciaefoli Cav. } \\
\text { M. acuminata Ruiz et Pav. }\end{array}$ & Naranja \\
\hline Chinchircuma & M. viciaefoli Cav. var. hirsuta Meyen & Naranja profundo \\
\hline Ñucchu o Chchurin & Salvia opositiflora Ruiz et Pav. & Rojo brillante \\
\hline Ñucchu o Chchurin & S. tubiflora Smith & Rojo \\
\hline Sacha Ñucchu & S. dombeyi Epling & Rojo oscuro \\
\hline Sullu-Sullu & $\begin{array}{c}\text { Bomarea ovata, } \text { B. uniflora Vargas, } \\
\text { B. sanguinea Kränz }\end{array}$ & Rojo \\
\hline Amancay & Hymenocallis iridiflora & Blanco o Amarillo \\
\hline Chiwanway & Zephrantes tubiflora Schinz & Rojo vivo \\
\hline Chiwanway & Crocopsis fulgens $\mathrm{Pax}$ & $\begin{array}{c}\text { Rojo o Tubo amarillo y Limbo } \\
\text { rojo }\end{array}$ \\
\hline Maywa & $\begin{array}{c}\text { Stenomesson variegatum (Ruiz et Pav.) } \\
\text { Macbr }\end{array}$ & Rosa salmón o crema \\
\hline Chimpи o Fuchsia & Fuchsia boliviana Britton & Rojo oscuro o Púrpura \\
\hline
\end{tabular}

Fuente: Infante Vera 1962; Towle 1961; Vargas 1981.

juventud (Mulvany 2000-2002). Bertonio y González de Holguín, cuando se refieren a las personas jóvenes emplean la expresión "florida edad de moços", "flor de su hedad", en la "flor de edad"... (Bertonio 1984 [1612], Primera Parte: 94, 243; Segunda Parte: 156, 286; González Holguín 1989 [1608], Segunda Parte: 526). Encontramos la expresión "mozo" en un conjunto de oraciones usadas en el contexto de Intip Raymi que transcribieron Molina y Murúa. Los sacerdotes expresaban..."Oh Hacedor y Sol y Trueno, sed siempre mozos, no envejezcáis: todas las cosas estén en paz, multipliquen las gentes y haya comidas; y todas las demás cosas vayan siempre en aumento"... (Molina "El Cuzqueño" 1959 [1575]:36). Asimismo ..."Las cuales oraciones decían al Hacedor; y al sol le decían que el siempre fuese mozo"... (Molina "El Cuzqueño" 1959
[1575:36]). Este cronista relata oraciones similares en otros contextos (Molina "El Cuzqueño" 1959 [1575]:37). De acuerdo a Murúa: decían que... "El

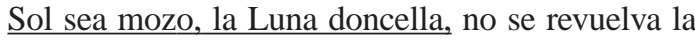
tierra, haya mucha paz. El Inga viva muchos años, hasta que sea viejo, no enferme, no tropiece, no caiga, viva bien, guárdenos y gobiérnenos"... (Murúa 1946 [1590]:271) (Subrayado nuestro). Un pedido para que las principales deidades incaicas fueran "mozos", jóvenes, para asegurar la continuidad vital del sistema social.

\section{Las Flores en los Rituales}

En el calendario del culto estatal las flores eran incluidas en diferentes actos rituales realizados en el Cuzco y regiones vecinas. Eran ofrendadas a las 
wakas, adornaban los caminos, eran quemadas y/u ofrendadas a las aguas, adornaban los gnomones y el palio bajo el cual descansaba el Inka y su esposa principal. En el transcurso de varios de estos ritos se rezaban las oraciones solicitando que las deidades fueran "siempre mozos" (Betanzos 1551-1987:72; Molina "El Cuzqueño" 1959 [1575]:38, 64, 86, 87, 349; Murúa 1946 [1590]:70, 257; Polo de Ondegardo 1916:21-22, citado en Arriaga 1999 [1621]:58-59 cita 181; Zuidema 1989a:277) (Tabla 2).

En la celebración de Capac Raymi, en el solsticio de diciembre, se desarrollaban varios rituales, durante los cuales los varones de la nobleza eran presentados a la sociedad Inka. Esto constituía una fase de renovación social y política, ya que se realizaba la selección de aquellos que cumplirían funciones en el gobierno, el sacerdocio y la administración del estado. Paralelamente se realizaban otras ceremonias para la delimitación de las fronteras sociales de los linajes de Inkas e Inkas de Privilegio (Zuidema 1989b y c). En este contexto los varones, incluido el Zapa Inka, usaban tocados de flores (Mulvany 2000-2002). Durante su trans- curso tenían lugar dos actos rituales relacionados con la iniciación de los jóvenes (Zuidema 1989b) (Figura 2).

\section{El Calendario Floral y Calendario Incaico}

El calendario incaico combinaba un año solar y un año lunar, integrado por doce meses lunares sinódicos (Molinié 1997). Posiblemente los meses comenzaban con la fase de novilunio (Ziólkowski 1996:75). El año lunar comenzaba aproximadamente el 9 de junio y finalizaba el 3 de mayo, con una duración de 336 días, distribuidos en 12 meses de 28 días. Esto producía un lapso de tiempo de 29 días de diferencia con el año solar (Molinié 1997). Entre mediados de abril y los primeros días de junio finalizaba el año. En ese período una constelación, la de Las Siete Cabrillas, no era visible o desaparecía del firmamento en la zona de Cuzco, particularmente en Yucay, y reaparecía a comienzos de junio cuando se las podía observar al amanecer. Este período de 37 días correspondía a la transición entre dos ciclos agrícolas, y coincidía con la cosecha del maíz y su almacenamiento en

Tabla 2. Contexto de empleo ritual de flores.

Ritual contexts in which flowers are used.

\begin{tabular}{|c|c|c|c|c|}
\hline Meses & $\begin{array}{l}\text { Ceremonias } \\
\text { rituales }\end{array}$ & $\begin{array}{l}\text { Adultos } \\
\underline{1}\end{array}$ & $\begin{array}{c}\text { Jóvenes } \\
\underline{2}\end{array}$ & $\begin{array}{c}\text { Actos rituales } \\
\underline{3}\end{array}$ \\
\hline $\begin{array}{l}\text { junio } \\
\text { julio }\end{array}$ & Intip rayme & Tocados de flores & & flores a wakas y en los caminos \\
\hline agosto & Chacrayapuy & Tocados de flores & & \\
\hline septiembre & $\begin{array}{l}\text { Coya raymi } \\
\text { situa } \\
\text { poray upia }\end{array}$ & Tocados de flores & & $\begin{array}{c}\text { flores en gnomones } \\
\underline{5}\end{array}$ \\
\hline $\begin{array}{c}\text { octubre } \\
\text { noviembre }\end{array}$ & Poray upia & & & flores a las aguas \\
\hline diciembre & Capac rayme & Tocados de flores & huaras orejeras & \\
\hline $\begin{array}{l}\text { enero } \\
\text { febrero }\end{array}$ & $\begin{array}{l}\text { huarachicuy } \\
\text { Mayucati }\end{array}$ & & flores en tocados & $\begin{array}{c}\text { flores a wakas y en los caminos } \\
\text { flores a las aguas }\end{array}$ \\
\hline marzo & Aymoray & & & $\begin{array}{c}\text { flores en gnomones } \\
\qquad \underline{4} \\
\text { flores en el palio del inka }\end{array}$ \\
\hline abril & Inca raymi & Tocados de flores & & $\underline{5}$ \\
\hline mayo & & & & \\
\hline
\end{tabular}

Fuente: 1 Cobo 1964 [1653]; Guaman Poma 1980 [1613] - 2 Garcilaso de la Vega 1976 [1609]; Guaman Poma 1980 [1613] $\underline{3}$ Betanzos 1987 [1551]; Molina 1959 [1575]; Murúa 1946 [1590]; Polo de Ondegardo 1916 en Arriaga 1999[1621] - 4 Zuidema 1969 c - $\underline{5}$ Zuidema 1969a. 


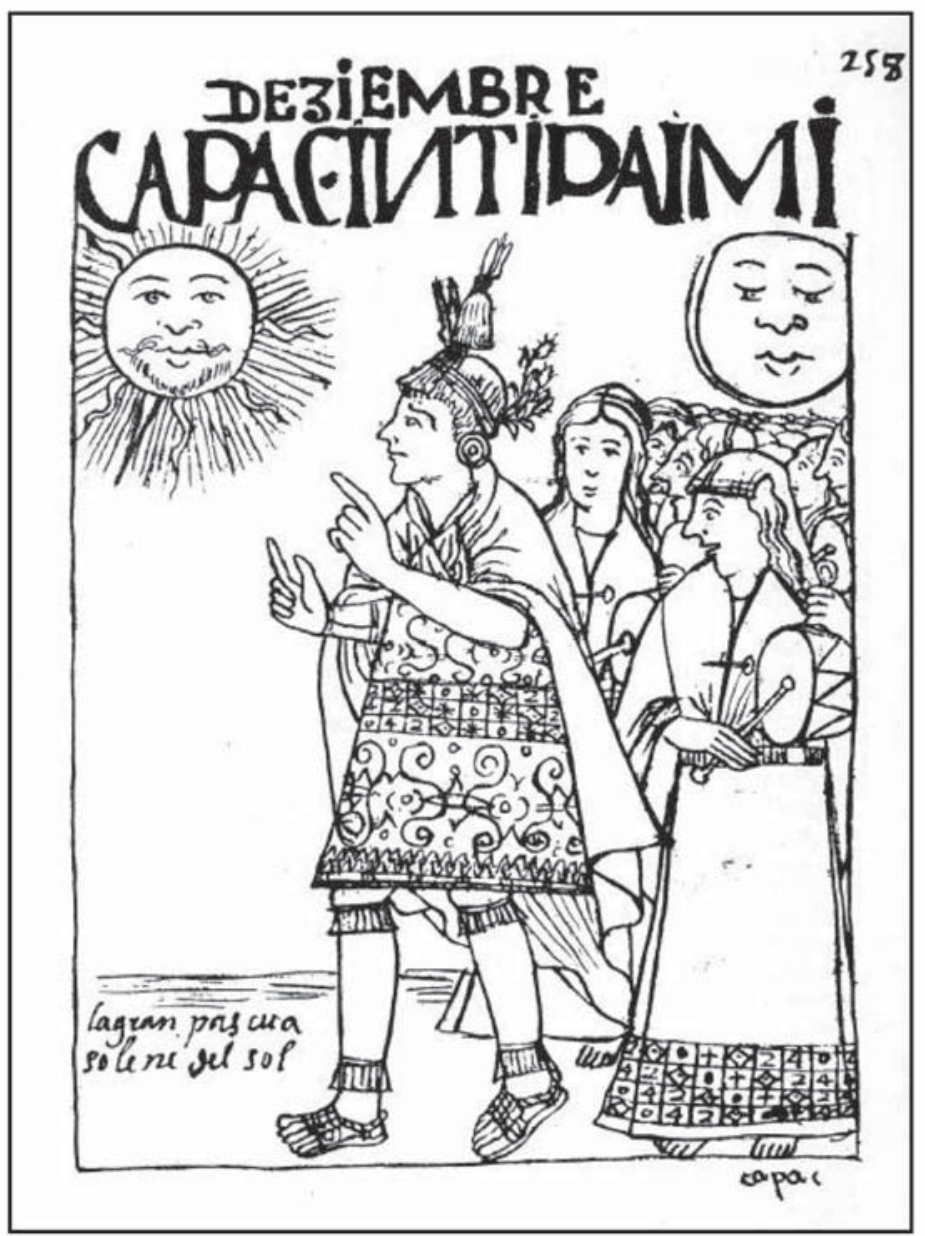

Figura 2. Capac Inti Raymi - el Inca con tocado de flores y el Señor Sol (Fuente: Guaman Poma de Ayala 1980 [1613]: folio 258).

Capac Inti Raymi - the Inca with a flower headdress and the Sun (after Guaman Poma de Ayala 1980 [1613]: folio 258).

collcas, uno de los nombres con que se designaba a esta constelación (Molinié 1997:702 y ss.). Corresponde también al lapso temporal que no era contabilizado por el sistema de ceques y que era interpretado como un momento de caos o desorden. La reaparición de Las Siete Cabrillas en junio señalaba el momento en el cual se restablecía el orden temporal, social y espacial, mediante las celebraciones rituales a las waqas (Molinié 1997: 704, citando comunicación personal de Zuidema). Las Siete Cabrillas u Oncoy eran las estrellas que eran veneradas para que no se secaran los maíces (Arriaga 1999 [1621]:59).

Las celebraciones rituales estatales más importantes se relacionaban con el ciclo agrícola anual
(Zuidema 1989c). Ziólkowski señala que se puede observar una oposición básica en el ritual del culto solar, entre las celebraciones que tenían lugar durante los solsticios de junio y diciembre, simbólicamente representado por una oposición entre Sol Joven (Punchaw o Churi Inti), en junio, que era pequeño y lejano según dibujos de Guaman Poma, y Sol Maduro o Señor Sol (Apu Inti), en diciembre, asociado a Wiraqucha (Ziólkowski 1996:51, citando a Demarest) (Figura 2).

Cuando confrontamos el calendario floral y el número de especies disponibles a lo largo del año encontramos que hay variaciones según los nombres vulgares. Una sola clase de flores, la Kantut o Kantuta, que incluye varias especies, se destaca 
porque es la única que está disponible a lo largo de todo el año. Consideramos que posiblemente esta circunstancia pudo contribuir a que fuera considerada como una de las flores más sagradas. Las restantes florecen en diferentes momentos, pero no durante todo el año (Tabla 3). Señalamos que de acuerdo al calendario floral el mayor número de especies que florecen en un momento dado se concentra en los meses de noviembre y diciembre; una segunda concentración se observa en septiembre. González Holguín señala un momento especial en el transcurso del año... "Paucar Huaray = tiempo de diuersidad de flores, tiempo florido en que brotan todas"... (González Holguín 1989 [1608], Primera parte:282). Proponemos que Paucar Huaray designa los meses de noviembre y diciembre, un "tiempo florido en que brotan todas"; posiblemente con esta designación se reconocía también el mes de septiembre (Tabla 3).

Cuando confrontamos Paucar Huaray con el calendario ritual podemos relacionarlo con la celebración de Capac Raymi. Durante su transcurso tenían lugar dos actos rituales relacionados con un rito de pasaje de los jóvenes entre los 12 y 15 años de edad, que tenía lugar en el Cuzco. El primero era la horadación de orejas de los adolescentes, como reconocimiento de su pertenencia al linaje de Manco Capac. El segundo, la colocación de huaras, que encerraba el significado de virilidad (Zuidema 1989b). Luego del rito de perforación del lóbulo de las orejas, a cada joven se le coloca- ban flores en el llauto ubicado sobre su cabeza. Garcilaso de la Vega señala que:

...Sin las insignias dichas, ponían en las cabezas, a los noveles, ramilletes de dos maneras de flores, unas que llaman cántut,...La otra manera de flor llaman chihuaihua;...Estas dos maneras de flores no las podían traer la gente común, ni los curacas, por grandes señores que fuesen, sino solamente los de la sangre real...También les ponían en la cabeza una hoja de yerba que llaman uiñay huaina,... (Garcilaso de la Vega 1976: Tomo II: Libro Sexto: Capítulo XXVII: 60) (Énfasis nuestro).

Desde este momento los varones, como adultos, podrían usar tocados de flores. Guaman Poma ilustra a Inga Roca con su hijo, posiblemente su heredero, ubicado a su izquierda, que lleva un tocado del que pende una flor, sugiriendo que ya atravesó este rito iniciación (Guaman Poma 1980 [1613]:73folio 102). El Capac Raymi en diciembre correspondía al momento del Sol Maduro o Señor Sol. De esta forma la transición de joven a adulto estaba acompañada por la colocación por primera vez de flores en el tocado (Tabla 4). Paucar Huaray o "tiempo florido en que brotan todas" las flores también se relacionan con la colocación de "pañetes" o huaras, que tenían el significado de virilidad.

Tabla 3. Calendario floral y paucar huaray.

The floral calendar and paucar huaray.

\begin{tabular}{|c|c|c|c|c|c|c|c|c|c|c|c|c|}
\hline Flores & Junio & Julio & Agosto & Septiembre & Octubre & Noviembre & Diciembre & Enero & Febrero & Marzo & Abril & Mayo \\
\hline Maywa & & & & ¿P H & & $P \quad H$ & $P \quad H$ & & & & & \\
\hline SulluSullu & & & & $A \quad U$ & & $A \quad U$ & $A \quad U$ & & & & & \\
\hline Amancaya & & & & $U \quad A$ & & $\begin{array}{ll}U & A\end{array}$ & $U \quad A$ & & & & & \\
\hline Chiwanway & & & & $\begin{array}{ll}C & R\end{array}$ & & $\begin{array}{ll}C & R\end{array}$ & $\begin{array}{ll}C & R\end{array}$ & & & & & \\
\hline Ñucchu & & & & $A \quad A$ & & $A \quad A$ & $A \quad A$ & & & & & \\
\hline Cantuta & & & & $R \quad Y$ ? & & $R \quad Y$ & $R \quad Y$ & & & & & \\
\hline \multicolumn{13}{|c|}{ Chinchincuma } \\
\hline \multicolumn{13}{|c|}{ SachaÑucchu (2) } \\
\hline Сhimpu (2) & & & & & & & & & & & & \\
\hline
\end{tabular}

Fuente: González Holguín 1989 [1608]; Infante Vera 1962; Towle 1961; Vargas 1981. 
Alternativamente otra lectura del calendario floral es que durante los meses de mayo y junio, cuando florecían menor variedad de flores, era el momento entre los dos ciclos agrícolas ( 3 de mayo y 9 de junio), vinculando el comienzo del año a las celebraciones de Intip Raymi y la manifestación del Sol Joven. Este era un momento connotado como caos y desorden. Postulamos que la oposición entre escasez y abundancia de flores (Paucar Huaray) se relaciona con la oposición Sol Joven y Sol Maduro, y dos de las celebraciones incaicas más importantes Intip Raymi y Ccapac Raymi. Podemos relacionar esos dos momentos con otra oposición: la de los varones jóvenes sin tocado de flores con la de los adultos con tocados de flores. Una tercera lectura es aquella que relaciona la escasez de flores con caos y desorden. En el extremo opuesto Paucar Huaray (abundancia de flores) sugiere orden y equilibrio (Tabla 4).

\section{Conclusiones}

Durante el período Colonial los vasos y tejidos compartían un conjunto de atributos relacio- nados con los motivos y su distribución espacial. Las flores, keros y unkus se relacionaban con las celebraciones del calendario ritual. Los hombres se adornaban con tocados de flores y ofrendaban flores a las wakas y las desparramaban por los caminos. Todo se vestía de flores, hombres y paisajes, una transformación que otorgaba cualidades de hermosura extrema, es decir algo "notable" o "sobresaliente", una manifestación de "alteridad" como señala Guchte, citando a Cobo (Guchte 2000:150). Una manifestación de belleza como mediación (Cereceda 1988).

Las flores constituían metáforas significativas. Su presencia en la banda inferior de los keros relacionaba los calendarios floral y ceremonial. La abundancia de la variedad de flores era Paucar Huaray, relacionado a Capac Raymi, al Sol Maduro o Señor Sol. La ausencia o menor cantidad de variedades de flores, por oposición se relacionaban con Intip Raymi, Sol Joven, comienzo del año, con su connotación de desorden.

Pintar y tejer flores en keros y unkus significaba proponer una mediación entre el caos y el orden, en un mundo en transformación, buscando la

Tabla 4. Calendario ritual, paucar huaray y posición del sol.

The floral calendar, pacar huaray, and positions of the sun.

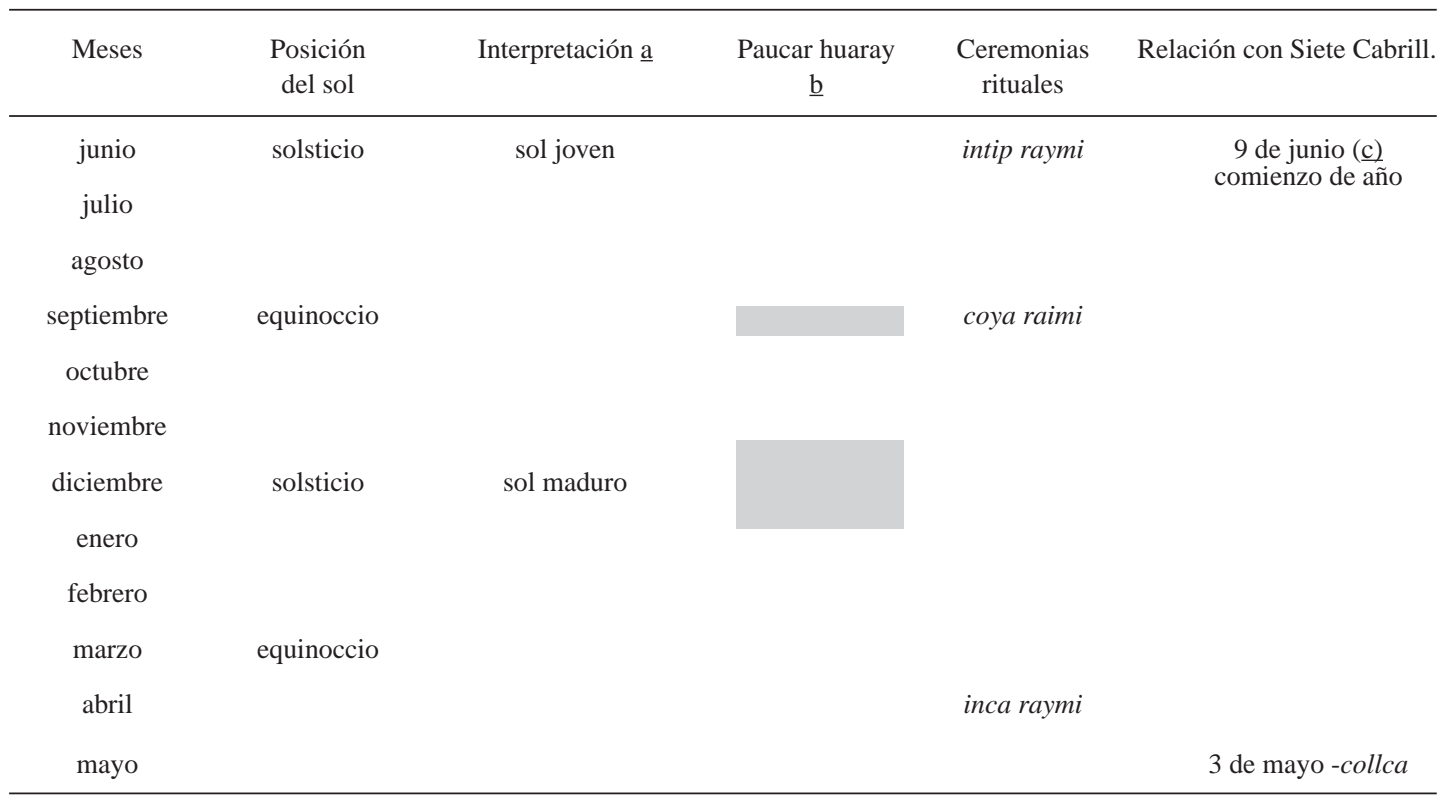

Fuente: a Demarest en Ziólkowski 1996; ㅁ González Holguín 1989 [1608]; c Molina 1959[1575]; Murúa 1946 [1590]; Molinié 1997. 
misma cualidad mediadora de los hombres que usaban tocados de flores. Se relacionaban con un ideal de juventud, representado por las flores, una metáfora de la eternidad, similar a la colocación de las hojas de Viñay Waina a los jóvenes iniciados ya que el nombre de estas hojas significaba "siempre joven".

Agradecimientos: A los evaluadores quienes realizaron oportunas observaciones.

\section{Referencias Citadas}

Arriaga, P.J.

1999 [1621] La Extirpación de la Idolatría en el Piru. Estudio preliminar y notas de Enrique Urbano. Centro de Estudios Regionales Andinos "Bartolomé de Las Casas", Cuzco.

Bertonio, L.

1984 [1612] Vocabulario de la Lengua Aymara. Reimpresión Facsimilar, 2 Partes. Ceres, Serie Documentos Históricos, $\mathrm{N}^{\circ}$ 1, agosto de 1984, Cochabamba.

Betanzos, J. de

1987 [1551] Suma y narración de los Incas. Transcripción, notas y prólogo por María del Carmen Martín Rubio. Atlas, Madrid.

Cereceda, V.

1988 Aproximaciones a una estética Aymara-Andina: de la belleza al tinku. En Raíces de América. El Mundo Aymara, compilado por X. Albó; pp. 283-356, Alianza, Sociedad Quinto Centenario, Madrid.

1990 A partir de los colores de un pájaro. Boletín del Museo de Arte Precolombino 4:57-104.

Cobo, B.

1964 [1653] Historia del Nuevo Mundo. Dos tomos. Biblioteca de Autores Españoles, Madrid.

Cummins, T.

1993 La representación en el siglo XVI: la imagen colonial del Inca. En Mito y Simbolismo en los Andes. La Figura y la Palabra, compilado por H. Urbano; pp. 87-136. Centro de Estudios Regionales Andinos "Bartolomé de Las Casas", Cusco.

Dobres, M.A.

2000 Technology and Social Agency. Outlining a Practice Framework for Archaeology. Blackwell, Oxford.

Estenssoro, J.C.

1993 La plástica colonial y sus relaciones con la gran rebelión. En Mito y Simbolismo en los Andes. La Figura y la Palabra, compilado por H. Urbano, pp. 157-182. Centro de Estudios Regionales Andinos "Bartolomé de Las Casas", Cusco.

Flores Ochoa, J.A.

1997 La missa andina. En Homenaje a Maria Rostworowski, Arqueología, Antropología e Historia en los Andes, editado por R. Varon Gavia y J. Flores Espinoza, pp. 717-728. Instituto de Estudios Peruanos, $1^{a}$ Ed., Banco Central de Reserva del Perú, Lima.

Garcilaso de la Vega, I.

1976 [1609] Comentarios Reales de los Inkas. Biblioteca Ayacucho. Dos tomos, Venezuela.

Gisbert, T.

1999a La serpiente Amaru y la conquista del Antisuyu: una historia alternativa. En El Paraíso de los Pájaros Parlantes. La Imagen del Otro en la Cultura Andina, editado por
Teresa Gisbert, pp. 85-95. Plural, Universidad Nuestra Señora de La Paz, La Paz.

1999b El paraíso de los pájaros parlantes. En El Paraíso de los Pájaros Parlantes. La Imagen del Otro en la Cultura Andina, editado por Teresa Gisbert, pp. 149-181. Plural, Universidad Nuestra Señora de La Paz, La Paz, Bolivia.

Gisbert, T., S. Arze y M. Cajías

1992 El Arte Textil y el Mundo Andino. TEA, $2^{\mathrm{a}}$ ed., Buenos Aires.

González Holguín, D.

1989 [1608] Vocabulario de la lengua general de todo el Perú llamada lengua Qquichua o del Inca. Presentación de R. Matos. Prólogo de R. Porras Barrenechea. Edición Facsimilar de la versión de 1952. Universidad Nacional Mayor de San Marcos, Lima.

Guaman Poma de Ayala, F.

1980 [1613] Nueva Coronica y Buen Gobierno. Biblioteca Ayacucho. Dos tomos, Venezuela.

Guchte, M. v. d.

2000 The Inca cognition of landscape: archaeology, ethnohistory and the aesthetic of alterity. En Archaeologies of Landscape. Contemporary Perspectives, editado por Wendy Ashmore y A. Bernard Knapp; pp. 149-168. $1^{\text {st }}$. ed. reprinted, Blackwell, Oxford.

Infante Vera, J.G.

1962 Estudio taxonómico, histológico y etnobotánico de algunas plantas útiles del Perú. Contribución a la etnobotánica peruana. Separata de Rev. Ciencias 11-21 Trimestre, Año LXIV, No 11 , Lima.

Iriarte, I.

1993 Las túnicas incas en la pintura colonial. En Mito y Simbolismo en los Andes. La Figura y la Palabra, compilado por H. Urbano, pp. 53-86. Centro de Estudios Regionales Andinos "Bartolomé de Las Casas", Cusco.

Letchman, $\mathrm{H}$.

1984 Metalurgia superficial precolombina. Investigación y Ciencia 95:20-30.

1997 El bronce arsenical y el Horizonte Medio. En Homenaje a Maria Rostworowski, Arqueología, Antropología e Historia en los Andes, editado por R. Varon Gavia y J. Flores Espinoza, pp. 153-186. Instituto de Estudios Peruanos, Banco Central de Reserva del Perú, $1^{\text {a }}$ Ed., Lima.

Molina "El Cuzqueño", C. d.

1959 [1575] Ritos y Fábulas de los Incas. Futuro, Buenos Aires.

Molinié, A.

1997 Buscando una historicidad andina: una propuesta antropológica y una memoria hecha rito. En Homenaje a Maria Rostworowski, Arqueología, Antropología e Historia en los Andes, editado por R. Varon Gavia y J. Flores 
Espinoza, pp. 691-708. Instituto de Estudios Peruanos, Banco Central de Reserva del Perú, $1^{\text {a }}$ Ed., Lima.

Mulvany, E.

1984 Motivos fitomorfos de alucinógenos en Chavín. Chungara 12:243-254.

1995 Posibles fuentes de alucinógenos en Wari y Tiwanaku: cactus, flores y frutos. Chungara 26:185-209.

2000-2000 Flores para los Incacuna, Haua Incas y Uaccha Incas. Cuadernos del Instituto Nacional de Antropología y Pensamiento Latinoamericano 19: 441-458.

Murúa, M.D.

1946 [1590] Historia del Origen y Genealogía Real de los Reyes Incas del Perú. Introducción, notas y edición por C. Bayle, S.J. Consejo Superior de Investigaciones Científicas, Instituto Santo Toribio de Mogrovejo, Madrid.

Rowe, J.H.

1961 The chronology of Inka wooden cups. En Precolumbian Art and Archaeology. Essay 22: 317-341.

Soldi, A.M.

1997 Un inédito de Toribio Mejia Xesspe: "Los keros de Chillwa 1925". En Homenaje a Maria Rostworowski, Arqueología, Antropología e Historia en los Andes, editado por R. Varon Gavia y J. Flores Espinoza, pp. 77-91. Instituto de Estudios Peruanos, Banco Central de Reserva del Perú, $1^{\text {a }}$ Ed., Lima.
Stastny, F.

$1993 \mathrm{El}$ arte de la nobleza inca y la identidad andina. En Mito y Simbolismo en los Andes. La Figura y la Palabra, compilado por H. Urbano, pp. 137-156. Centro de Estudios Regionales Andinos "Bartolomé de Las Casas", Cusco.

Towle, M.

1961 The Ethnobotany of Pre-Columbian Peru. Foreword by G.R. Willey. Aldine Publishing Company, Chicago.

Vargas, F.C.

1981 Plant motifs on Inka ceremonial vases from Peru. Reprinted from Botanical Journal of the Linnean Society 82: 313-325.

Ziólkowski, M.S.

1996 La Guerra de los Wawqui. Los Objetivos y los Mecanismos de la Rivalidad dentro de la Elite Inka, Siglos $X V$-XVI. $1^{a}$ edición, Abya-Yala, Quito.

Zuidema, R.T.

1989a La cuadratura del círculo en el antiguo Perú. En: Reyes y Guerreros. Ensayos de Cultura Andina, compilado por M. Burga, pp. 273-305. Perú.

1989b El león en la ciudad. En Reyes y Guerreros. Ensayos de Cultura Andina, compilado por M. Burga, pp. 306-383. Perú.

1989c El Ushnu. En Reyes y Guerreros. Ensayos de Cultura Andina, compilado por M. Burga, pp. 402-454. Perú. 